\title{
An Approach to Economics-Environmental Relations from Expanding the Input-Output System
}

\author{
Trinh Bui*, Thai Nguyen Quang \\ Vietnam Development Research Institute, Hanoi, Vietnam \\ Email: ^buitrinhcan@gmail.com, thai.nguyenquang@gmail.com
}

How to cite this paper: Bui, T., \& Quang, T. N. (2021). An Approach to Economics-Environmental Relations from Expanding the Input-Output System. Theoretical Economics Letters, 11, 56-62. https://doi.org/10.4236/tel.2021.111004

Received: January 6, 2021

Accepted: February 7, 2021

Published: February 10, 2021

Copyright $\odot 2021$ by author(s) and Scientific Research Publishing Inc. This work is licensed under the Creative Commons Attribution International License (CC BY 4.0).

http://creativecommons.org/licenses/by/4.0/

\begin{abstract}
In the last few decades, the relationship between economy and environment has become the concern of many scholars, there have been many studies linking economic development and environmental pollution. Even the United Nations has introduced an economic-environmental linkage framework such as System of Environmental-Economics Accounts (SEEA) that is compatible with the System of National Accounts (SNA). This study attempts to provide a theoretical framework based on Miyazawa's ideas on interregional model and demographic-economic model in order to improve the integration between economy and waste.
\end{abstract}

\section{Keywords}

Economic, Environmental, Input-Output, Matrix, Multipliers

\section{Introduction}

For decades, scholars have attempted to propose models of the linkage between the economy and the environment through Leontief (1970)'s input-output model. It was he who first came up with the idea of combining economics and environment in a scientific activity (seminal paper). Leontief and a number of later scholars such as McNicoll \& Blackmore (1993) and McGregor et al. (2001) used a direct production waste coefficient matrix to do empirical studies applying such an approach to modeling air pollution in Scotland. This type of work quantifies the impact of economy to the environment, in terms of emissions. However, these studies do not track further environmental responses to the economy, regarding the activity generated in environmental cleanup. The input-output model can be extended to study this problem with pollution re- 
duction activities.

This research tries an attempt, a more detailed introduction to the literature related to the linkage between the economy and the environment through Leontief's input-output model.

There are some applications of Leontief's environmental input-output model to study the impact of economic activities on the environment through air pollutions in Vietnam such as studies of Trinh \& Phong (2013), Trinh \& Hoa (2017), Hung \& Trinh (2019).

Studies around Leontief's input-output model include Flick (1974); Steenge (1978); Lowe (1979); Qayum (1991); Arrous (1994) and Luptacik \& Böhm (1999). Allan, Hanley, McGregor, Swales, \& Turner (2004). These studies extend and applying the Leontief system pollution model in both sides: Emission economy and waste treatment.

The using of input-output system to combine economic and environment is also given in "System of Environmental-Economic Accounting (SEEA)" by United Nation. This issue is also mentioned in "Handbook of input-output table compilation and analysis" by United Nation.

However, these extensions do not yet have the perfect combination of environmental and economics by "inter-environmental-economics" type. This study tries an attempt to extend Leontiefs input-output model according to type of Miyazawa's (1976) inter-regional and demographic-economic models in order to linkage between environmental and economics in a more uniform way

\section{Approach}

Miyazawa's concept of the income multipliers was designed to analyze the structure of income distribution by opening columns by consumption type and corresponding income streams in the standard Leontief model. These ideas are also incorporated in the familiar social matrix accounting systems developed by Stone (1961), Pyatt and Roe (1977), and in the parallel development of the demographic-economic model. Relating to Batey and Madden (1981). In a sense, Miyazawa's system is perhaps the most complex in terms of how it extends the familiar input-output formula. In this study substitute the variables of consumptions and incomes are the amount of cost that the sectors in economy have to buy products (at rows) of waste reduction activity (at columns)

Leontief's input-output system is expanded with $A_{11}$ is an endogenous direct input coefficient matrix; $A_{21}$ is the coefficient matrix for the industries to pay for environmental cleaning, $A_{12}$ is the cost coefficient matrix. waste treatment activities use products as input costs, $A_{22}$ is the cost coefficient matrix when waste treatment activities also pay for environmental cleaning (because in the process of disposing of one type of waste it is possible to release another type of waste); $X_{1}$ and $X_{2}$ are production value vectors for the manufacturing and waste treatment industries. Calling $E_{1}$ the direct waste from production, $E_{2}$ being the waste generated in the waste treatment process, $E_{3}$ being the waste 
from final consumption and from other sources, $Y_{1}$ and $Y_{2}$ are the final demand vector of the products of economy and environmental protection costs, $V_{1}$ and $V_{2}$ are the value added of the manufacturing sectors and waste disposal operations sectors. So, the input-output expansion has structure below (Table 1):

\section{Approach model 1:}

From the structure of the expanded input-output table above, we have:

$$
\begin{gathered}
A_{11} X_{1}+A_{12} X_{2}+Y_{1}=X_{1} \\
A_{21} X_{1}+A_{22} X_{2}+Y_{2}=X_{2}
\end{gathered}
$$

Suppose to treat a unit of waste requires $\delta$ dollar, in the total waste $E$ need to treat the amount of waste is $\alpha E(\alpha<1)$, so production value of $X_{2}=\delta \cdot \alpha \cdot E$ for abating required amount of waste disposal. Relation (1) and (2) we have:

$$
\begin{aligned}
\left(\sum Y_{1}+\sum Y_{2}\right)= & \left(\sum X_{1}+\sum X_{2}\right)-\left[\left(\sum A_{11} X_{1}+\sum A_{12} X_{2}\right)\right. \\
& \left.+\left(\sum A_{21} X_{1}+\sum A_{22} X_{2}\right)\right]
\end{aligned}
$$

Notice that:

$$
\left(\sum X_{1}+\sum X_{2}\right)-\left(\sum A_{11} X_{1}+\sum A_{21} X_{1}\right)=\mathrm{GDP}
$$

So:

$$
\sum Y_{1}=\mathrm{GDP}-\left(\sum A_{12} X_{2}+\sum A_{22} X_{2}\right)-\sum Y_{2}
$$

where: $\sum Y_{1}$ can call "Green GDP” after subtracting the cost of cleaning the environment of both production and final consumption or can be considered as an “environmental tax".

Rewrite relations (1) and (2) as the matrix form we have:

$$
\left[\begin{array}{l}
X_{1} \\
X_{2}
\end{array}\right]=\left[\begin{array}{ll}
A_{11} & A_{12} \\
A_{21} & A_{22}
\end{array}\right] \cdot\left[\begin{array}{l}
X_{1} \\
X_{2}
\end{array}\right]+\left[\begin{array}{l}
Y_{1} \\
Y_{2}
\end{array}\right]
$$

Put:

$$
\begin{gathered}
B=\left[\begin{array}{ll}
A_{11} & A_{12} \\
A_{21} & A_{22}
\end{array}\right] \\
X=\left[\begin{array}{l}
X_{1} \\
X_{2}
\end{array}\right]
\end{gathered}
$$

Table 1. The input-output table expands for the linking between economy and environment.

\begin{tabular}{ccccc}
\hline & \multicolumn{2}{c}{ Intermediate cónumption } & Final demand & Gross output \\
\hline \multirow{2}{*}{ Intermediate input } & $A_{11} X_{1}$ & $A_{12} X_{2}$ & $Y_{1}$ & $X_{1}$ \\
& $A_{21} X_{1}$ & $A_{22} X_{2}$ & $Y_{2}$ & $X_{2}$ \\
Value added & $V_{1}$ & $V_{2}$ & Gross value added (GVA) & \\
Gross input & $X_{1}$ & $X_{2}$ & & \\
Residuals & $E_{1}$ & $E_{2}$ & $E_{2}$ & $E$ \\
\hline
\end{tabular}




$$
Y=\left[\begin{array}{l}
Y_{1} \\
Y_{2}
\end{array}\right]
$$

Relation (5) returns to the standard Leontief relation

$$
X=(I-B)^{-1} \cdot Y
$$

Put:

$$
U=(I-B)^{-1}
$$

The $U$ matrix can include sub-matricies as follow:

$$
U=\left[\begin{array}{ll}
U_{11} & U_{12} \\
U_{21} & U_{22}
\end{array}\right]
$$

where: $U_{11}$ and $U_{22}$ are enlarge Leontief inverse matricies, So $U_{11}$ and $U_{22}$ include:

- Direct effects: $A_{11}, A_{22}$

- Indirect effects: $\left[\left(I-A_{11}\right)^{-1}-A_{11}\right]$ and $\left[\left(I-A_{22}\right)^{-1}-A_{22}\right]$

- Induced effects by waste treatment activities: $\left[U_{11}-\left(I-A_{11}\right)^{-1}\right]$ and $\left[U_{22}-\left(I-A_{22}\right)^{-1}\right]$

$U_{21}$ is seen as a matrix of charges (taxes) to be paid per unit increase of the final products in order to reduce the required amount of waste. $U_{12}$ represents the cost induced by the increase in waste resulting from a changing on the end product.

\section{Approach model 2:}

Call: $E_{1}=\left(e_{1 i j}\right)_{(k \times n)}$ With: $e_{1 i j}=E_{1 i j} \cdot X_{1 j}$,

where: $k$ is number of residuals and $n$ is number of sectors in economy

And:

$$
E_{2}=\left(e_{2 i j}\right)_{(k \times m)} \text { With } e_{2 i j}=X_{2 j}
$$

Where: $\mathrm{m}$ is number residual treamnet activities

On the other hand notice that:

$A_{12} \cdot X_{2}=X_{12}$ presents intermediate input matrix of residual treatment activities

Put: $h_{i j}=X_{12 i j} / E$

From the structure of the model we have:

$$
\begin{array}{r}
A_{11} \cdot X_{1}+h \cdot E+Y_{1}=X_{1} \\
e_{1} \cdot X_{2}+e_{2} \cdot X_{2}+E_{3}=E
\end{array}
$$

Write the system of Equations (7) and (8) as matrix form we have:

$$
\left[\begin{array}{c}
X_{1} \\
E
\end{array}\right]=\left[\begin{array}{cc}
A_{11} & h \\
e_{1} & e_{2}
\end{array}\right] \cdot\left[\begin{array}{c}
X_{1} \\
E
\end{array}\right]+\left[\begin{array}{c}
Y_{1} \\
E^{3}
\end{array}\right]
$$

To implement the above relationship according to the Schur-Miyazawa formula (Miyazawa, 1976) and Sonis \& Hewings (1993), we have: 


$$
\left[1-\left[\begin{array}{cc}
A_{11} & h \\
e_{1} & e_{2}
\end{array}\right]\right]^{-1}=\left[\begin{array}{cc}
\Delta_{1} & \Delta_{1} \cdot h \cdot\left(I-e_{2}\right)^{-1} \\
\Delta_{2} \cdot e_{1} \cdot\left(I-A_{11}\right)^{-1} & \Delta_{2}
\end{array}\right]
$$

In relation (10) $\Delta_{1}$ and $\Delta_{2}$ include direct, indirect and diffuse effects. According to the Miyazawa definition $\Delta_{1}$ and $\Delta_{2}$ are the combination of an inner factor and an external factor.

Inrternal multipliers for economics: $\left(I-A_{11}\right)^{-1}$.

Inrternal multipliers for environmentalchất thải: $\left(I-e_{2}\right)^{-1}$.

External multipliers. $\left[I-\left(I-A_{11}\right)^{-1} \cdot h \cdot\left(I-e_{2}\right)^{-1} \cdot e_{1}\right]^{-1}$ are considered as the spillover by waste treatment activities to the output of other sectors of the economy. $\left[I-\left(I-e_{2}\right)^{-1} \cdot e_{1} \cdot\left(I-A_{11}\right)^{-1} \cdot h\right]^{-1}$ are the waste spillover effects of the economy stimulated by the input to waste disposal activities.

$\Delta_{2} \cdot e_{1} \cdot\left(I-A_{11}\right)^{-1}$ are residuals that induced by a unit increase of final demand

$\Delta_{1} \cdot h \cdot\left(I-e_{2}\right)^{-1}$ are increased waste disposal to accommodate an increased unit of waste.

\section{Discussion}

Due to no data for making empirical study, so, the paper provides a theoretical framework that offers a new way for studying the relationship between the economy and the environment.

This study expands the basic relationship of the traditional input-output model with the notions of internal and external factors by Miyazawa to create the relationship between emissions generated by the economy and waste disposal activities. In this study, we attempt to determine the role of the waste multiplier in relation to the sensitivity analysis and the aggregate interactions between waste and waste disposal.

The theoretical framework developments provided here may set the stage for some important empirical analysis. Furthermore, the structure of an economy as revealed by many standard macroeconomic models is often conceal important differences in the nature of internal and external interdependence. For example, Waste reduction activities not only induce to the output of other sectors of the economy but also generate other wastes. The $U_{21}$ matrix can also allow to determine the costs that industries have to pay for each industry and each type of waste. Moreover, in the approarch model 2 allows to know how amounts residuals increase when a unit final demand increases.

However, limit of this research to be there is no data for making empirical study, so, this research is hoping to get some attention to get the data needed for a later experimental work.

\section{Conflicts of Interest}

The authors declare no conflicts of interest regarding the publication of this paper. 


\section{References}

Allan, G., Hanley, N. D., McGregor, P. G., Swales, J. K., \& Turner, K. R. (2004). An Extension and Application of the Leontief Pollution Model for Waste Generation and Disposal in Scotland. Glasgow: University of Strathclyde.

Arrous, J. (1994). The Leontief Pollution Model: A Systematic Formulation. Economic Systems Research, 5, 105-107. https://doi.org/10.1080/09535319400000008

Batey, P. W. J., \& Madden, M. (1981). Demographic-Economic Forecasting within an Activity-Commodity Framework: Some Theoretical Considerations and Empirical Results. Environment and Planning A: Economic and Space, 13, 1067-1083. https://doi.org/10.1068/a131067

Hung, D. M., \& Trinh, B. (2019). Forestry Sector and Policies on Sustainable Development in Vietnam: Analyze from the Input-Output Model. International Journal of Social and Administrative Sciences, 4, 253-266. https://doi.org/10.18488/journal.136.2019.42.253.266

Flick, W. A. (1974). Environmental Repercussions and the Economic Structure: An Input-Output Approach: A Comment. Review of Economics and Statistics, 56, 107-109. https://doi.org/10.2307/1927534

Leontief, W. (1970). Environmental Repercussions and the Economic Structure: An Input-Output Approach. Review of Economics and Statistics, 52, 262-277. https://doi.org/10.2307/1926294

Lowe, P. D. (1979). Pricing Problems in an Input-Output Approach to Environmental Protection. Review of Economics and Statistics, 61, 110-117. https://doi.org/10.2307/1924837

Luptacik, M., \& Böhm, B. (1999). A Consistent Formulation of the Leontief Pollution Model. Economic Systems Research, 11, 263-275.

https://doi.org/10.1080/09535319900000018

McGregor, P. G., McNicoll, I. H., Swales, J. K., \& Turner, K. R. (2001). Who Pollutes in Scotland? A Prelude to an Analysis of Sustainability Policies in a Devolved Context. Quarterly Economic Commentary, 26, 23-32.

McNicoll, I. H., \& Blackmore, D. (1993). A Pilot Study on the Construction of a Scottish Environmental Input-Output System. Report to Scottish Enterprise, Glasgow: Department of Economics, University of Strathclyde.

Miyazawa, K. (1976). Input-Output Analysis and the Structure of Income Distribution. Heidelberg: Springer-Verlag. https://doi.org/10.1007/978-3-642-48146-8

Pyatt, G., \& Roe, A. N. (1977). Social Accounting for Development Planning with Special Reference to Sri Lanka. Cambridge: Cambridge University Press.

Qayum, A. (1991). Books and Notes. Economic Systems Research, 3, 428-430. https://doi.org/10.1080/09535319100000033

Sonis, M., \& Hewings, G. J. D. (1993). Hierarchies of Regional Sub-Structuresand Their Multipliers within Input-Output Systems: Miyazawa Revisited. Hitotsubashi Journal of Economics, 34, 33-44.

Steenge, A. E. (1978). Environmental Repercussions and the Economic Structure: Further Comments. Review of Economics and Statistics, 60, 482-486.

https://doi.org/10.2307/1924178

Stone, R. (1961). Social Accounts at the Regional Level. In W. Isard, \& J. H. Cumberland (Eds.), Regional Economic Planning. Paris: Organisation for Economic Co-operation and Development. 
Trinh. B., \& Hoa, P. L. (2017). Comparing the Economic Structure and Carbon Dioxide Emission between Vietnam and China. VNU Journal of Science, 33, 1-11.

Trinh. B., \& Phong, N. V. (2013). Economic-Environmental Impact Analysis Based on the Changes of Economic Structures of HoChiMinh City (HCMC) and the Rest of Vietnam (ROV) (2000)-(2007). International Journal of Case Studies, 2, 1-34. 